\title{
CONTROL OF AGRICULTURAL LAND FLOODING BY USING REMOTELY PILOTED AIRCRAFT SYSTEM
}

\author{
Dmitrijs Gorelikovs, Margarita Urbaha \\ Riga Technical University, Latvia \\ dmitry.gorelikov@gmail.com, urbaha.margarita@gmail.com
}

\begin{abstract}
At present, the Geographic Information System (GIS) is one of the tools for obtaining detailed information about the condition of agricultural land with reference to its geographical position. The correct operation of GIS requires a database of objects (electronic charts) containing reliable, up-to-date information. The requirements and procedures of GIS data updating differ for various agricultural sectors. In some cases, the correction of chart databases has to be made within the shortest possible time. In other cases, a permanent, regular monitoring and updating of information in the long term are required. In addition to that, in emergencies, a combination of both above-mentioned approaches is applied. The article proposes the method, equipment and algorithm for making it possible to quickly correct the GIS data based on the results of controlling the flooding of agricultural land with the help of remotely piloted aircrafts. The article analyses the advantages of applying a Remotely Piloted Aircraft System (RPAS) with a system of automated cartographic information collection for creating charts of flooded areas, quick correction of these charts and monitoring the situation in real-time mode in cases when flood hazard has been announced. As a result, time and material costs can be minimized.
\end{abstract}

Keywords: information, geography, cartography, aircraft, correction.

\section{Introduction}

Taking into consideration the rapid development of technology within the last decades, the level of practical tasks set for all directions of agriculture development is constantly increasing as well. To solve these tasks, it is required to use specific systems, algorithms and implementations rather than general solutions. The development of specialized Geographic Information Systems (GIS) containing information about relevant objects with reference to their geographical position can be regarded as one of such tools. The wide possibilities of applying GIS are related to a greater choice of possible objects - from road carpet monitoring [1] and environmental pollution control [2;3] to observing the condition of agricultural areas [4] and woodlands [5]. One of the prospective directions of GIS application is agricultural land flooding control [6]. The possibility of acquiring, storing, analysing and graphically visualizing geographical data and related information on flooded areas will allow not only to conduct research based on the acquired data but also to forecast the likelihood of flooding and size of areas that may be flooded.

However, in order to ensure the correct operation of GIS, electronic charts (object databases) containing reliable and up-to-date information are required. The issue of the correct operation of GIS directly depends on the correspondence of electronic chart correction to the present moment. Currently applied flood control systems use sensors to collect data further transmitting them via GPS [7], radio frequencies [8] (Fig.1) or satellite communication [9].

At present, comparison of the positive and negative aspects for each of the above-mentioned data obtaining methods is investigated. However, if the research in using of satellite observation systems is quite active [10;11], the use of RPAs is considered only in cases where it is necessary to promptly obtain information in emergencies, and not on ongoing basis [12]. This article discusses disadvantages of satellite surveillance to determine flooding and shows the system which implementation will allow using the RPA, the simple terrain markers (without electronics) and a developed Data Collection System to receive real-time automated information about the observation area.

The drawback of all the above-mentioned methods lies in the obligatory presence of batteries for ensuring data transfer from sensors to a server for further data processing and storage. In addition to that, it is necessary to provide control subsystems allowing to confirm the operating condition of hightech sensors that have high production cost; and in case of sensor failure, it is required to ensure their replacement or repair within the shortest possible time.

Mere substitution of electronic sensors by common visual markers with a defined height for marking the level of possible flooding and with special marking (for example, a colour marker or pattern) easily recognizable from an aircraft (Fig. 2) can ensure the operation of the system without the necessity of replacing or repairing for decades. If the water level exceeds the defined height, the 
marker will not be visible, which after obtaining from the aircraft a photo of the observation area will allow to conclude that the area is flooded.

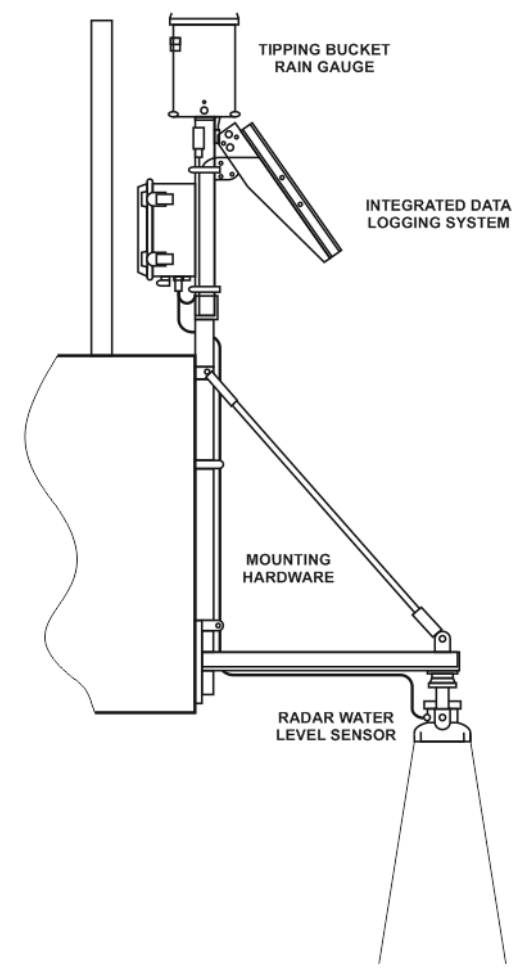

Fig. 1. Typical implementation of electronic flood control system with data transmitter [8]

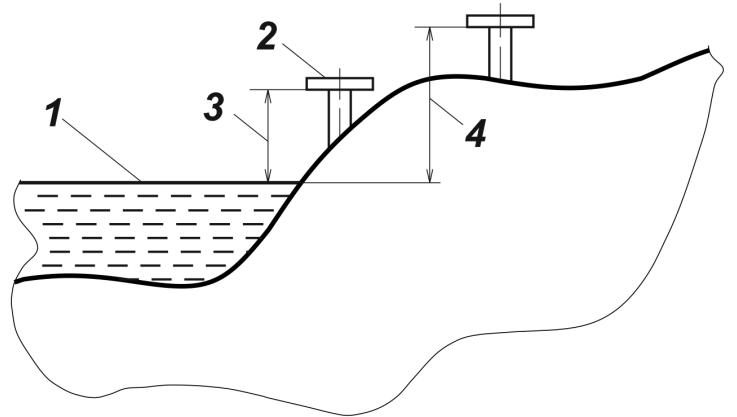

Fig. 2. Scheme of flood level control implementation by using special markers: 1 - standard water level; 2 - marker; 3 - marker height above the standard water level;

4 - marker height of the next flooding level

To carry out the video surveillance of such markers, it is necessary to ensure their routine observation allowing to maintain the prompt delivery of up-to-date information. This article considers the ways of controlling flood levels by ensuring the video surveillance of markers with the help of satellite systems or remotely piloted aircraft (RPA) systems.

\section{Research of new Data Collection System development and realization}

1. Flood Level Control by Using Satellite Systems.

This method includes the possibility of permanent or periodic (in certain periods of time) visual surveillance of selected objects (in our case, markers) from satellites located over the area in question. The aim of surveillance is to control the level of flooding based on obtained photographic images. Using this method, the accuracy of monitoring is substantially reduced due to the low resolution of satellite photography.

Besides, regulatory authorities impose a number of limitations on visual information transfer from satellites. For example, before 2014 it was forbidden by the United States Department of Commerce and Department of Defence to commercially sell images with a resolution exceeding 50 centimetres 
per pixel to third parties. So Digital Globe, the well-known commercial operator of several civilian satellites for remote Earth sensing and major supplier of satellite photography results (in particular for Google Maps/Earth and Virtual Earth) was able to offer satellites with a resolution exceeding 50 centimetres per pixel only in 2014, after being granted special permission by the United States Department of Commerce [13]. However, the general restriction - 25 centimetres per pixel - is currently in force. Moreover, it is rather difficult to obtain for satellite observations. The practical implementation of the latest generation of Digital Globe's satellites (WorldView-3) provides a maximum panchromatic camera resolution of up to 31 centimetres per pixel under perfect conditions.

What does this restriction mean? Fig. 3 presents the difference in photographs with various distance per pixel.

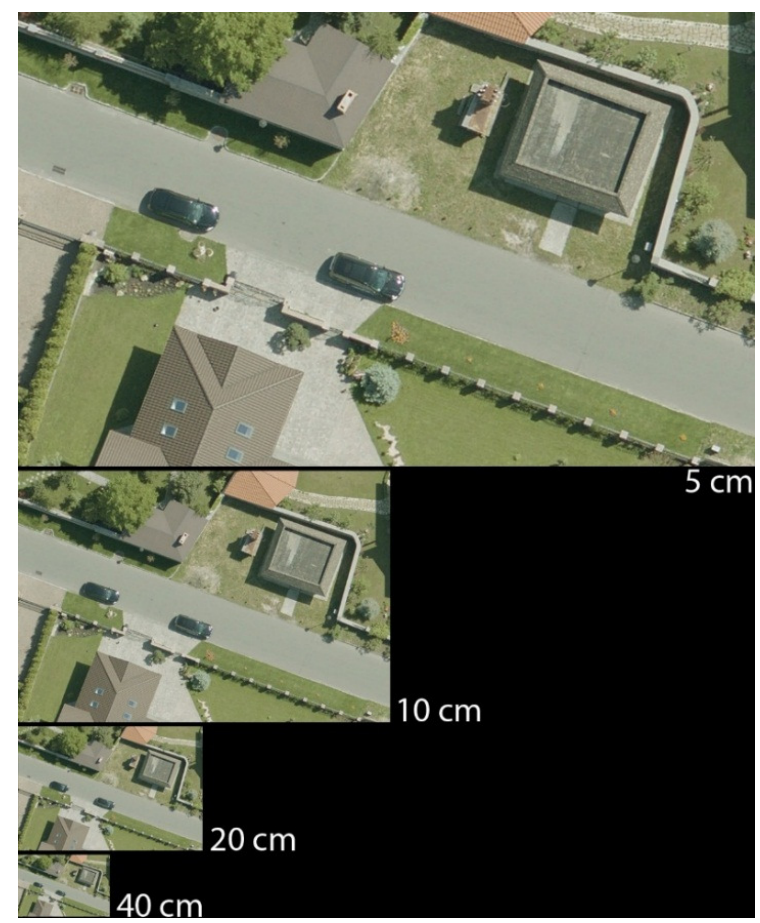

Fig. 3. Example of satellite photograph resolution

It is necessary to take into account that patterns for stable marker recognition in a photo by using software include areas of several tens of pixels both in horizontal and vertical directions rather than in a $3 \times$ 3-pixel matrix. Otherwise, it will be challenging to recognize the marker. However, with account of the above-mentioned restrictions, even under optimum conditions (for example, at 31 centimetres per pixel image resolution and a 10-pixel square recognition matrix) objects with a diameter of less than 3 metres are impossible to recognize. If the conditions are not optimum, it will also be challenging to recognize an object with a diameter of 5 or 10 metres.

In addition to that, it must be taken into account that in most cases conditions will not be perfect. Light refraction on atmospheric inhomogeneities imposes limitations on the maximum possible resolution when observing the Earth from space. This limitation depends on the state of the atmosphere and under favourable conditions (the morning orbit) is about half a meter per pixel. Sometimes, under very favourable conditions (very calm air), it reduces up to 30 centimetres. If at this moment a satellite with an optical resolution exceeding this restriction will appear and take a photo over this place, the photo will anyway have a resolution of not less than 30 centimetres per pixel. It is also necessary to take into account that such a coincidence, i.e. when a satellite appears at a certain place, is possible only by accident, because it is impossible to predict where and when such conditions will exist.

It is practically impossible to achieve a better resolution than 30 centimetres per pixel - even very calm air refracts light anyway.

So, a resolution of up to 50 centimetres per pixel can be achieved by improving the quality of optical systems. However, this is a limit. Any improvements will not be able to overcome atmospheric 
refraction; and no matter how advanced the optics may be, the recognition of objects less than 5-10 metres in a satellite photograph will always be related to a high probability of error.

Thus, the application of this method for determining the coordinates of objects less than 2 metres in diameter will be challenging due to the complexity of determining the presence of an object with account of the existing quality of satellite photography.

2. Flood Level Control by Using Remotely Piloted Aircraft.

Working with relatively small objects (in our case, up to one metre in diameter), well-known control methods are usually accompanied with aerial photography that allows to achieve higher spatial resolution of a photo in-situ yet has higher unit cost (expressed in monetary units per $\mathrm{m}^{2}$ ). At the same time, when using RPA photography as an additional source of information, the problem of unit cost can be solved by taking into account multiple differences in the cost of using specialized aviation and RPA for photography. The use of RPA makes it possible to obtain data in real time at minimum costs.

Before the beginning of the flight, the Cartographic Information System (CIS) with an RPA system can calculate the coordinates of markers based on the existing electronic chart and draw up an optimum flight plan(s) with account of the number of simultaneously used RPA. After flying around the area and obtaining photos of a real situation, CIS, taking into consideration the presence or absence of markers automatically determined by the object recognition subsystem [14] on electronic chart coordinates, can (in case of mismatch) make a decision regarding the necessity of making changes. After that, information about the absence of markers will be used for the calculation of flooded area (see Fig. 4 for an example).

A specialized RPA for cartographic data collection must comply with a number of technical requirements, such as suitability for operation in unfavourable weather conditions, possibility of a long-lasting flight (long enough to cover the required monitoring area), equipment with a photo-taking device ensuring quality that is good enough for recognizing objects, etc.

There is also required a professional implementation of the coastal segment of the control system using an RPA that must include several software modules responsible for:

1. flight plan made on the basis of the electronic chart of the area to be examined;

2. processing of photos made during the RPA flight;

3. determining the real location of objects;

4. making a decision on the necessity of correcting flooding parameters (markers).

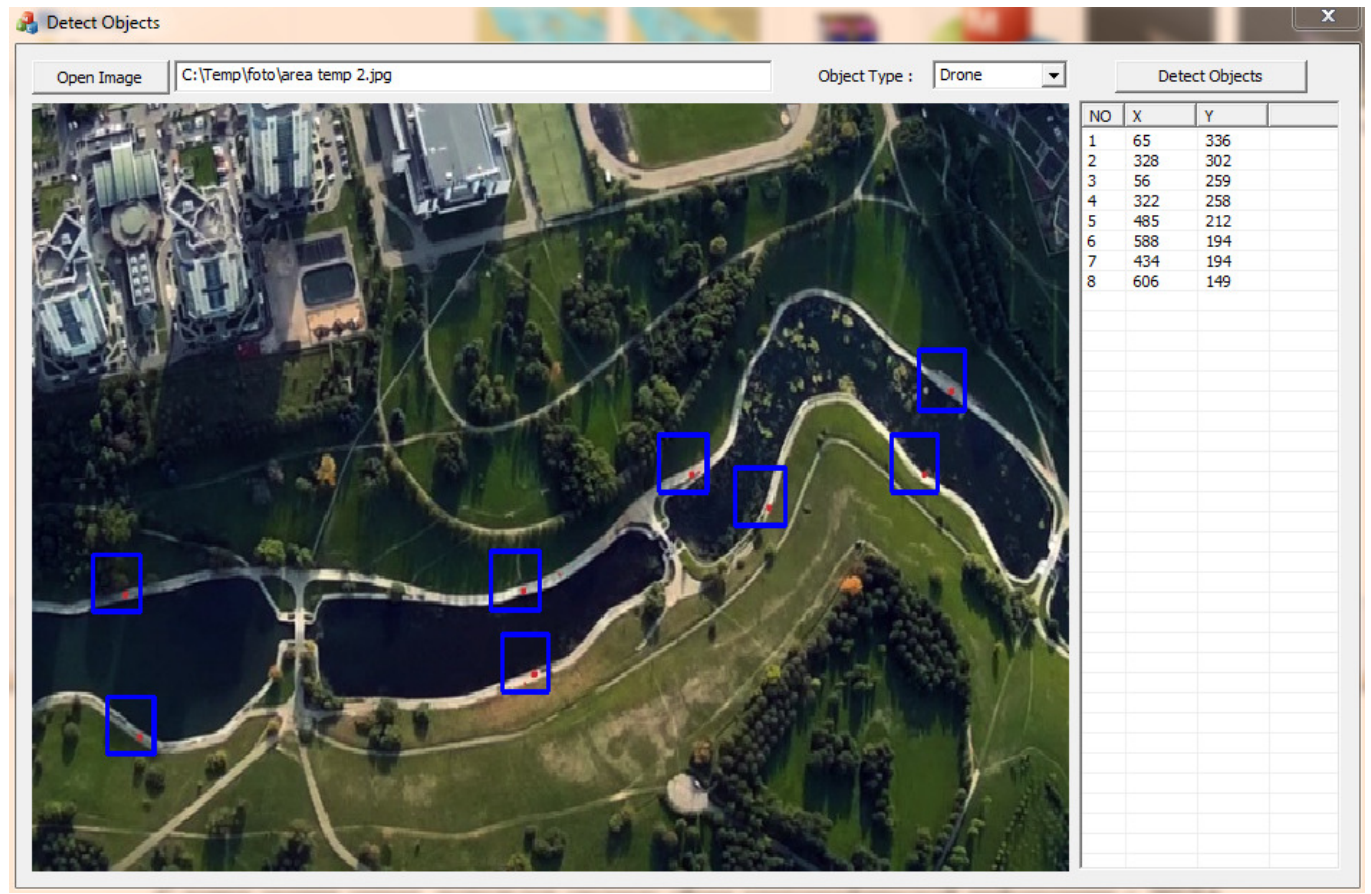

Fig. 4. Example of CIS determining presence of markers (the radius of a marker is 15 centimetres) 
After the development and commissioning of the system, no substantial expenditures will be needed. Maintenance of several RPA requires much less time and financial costs than maintenance of an aircraft or a helicopter, payment for satellite channels for data communication or installation and maintenance of hundreds of sensors.

\section{Conclusions}

Currently applied flood control systems use sensors to collect data, further transmitting them via GPS, radio frequencies or satellite communication.

The drawback of all the above-mentioned methods lies in the obligatory presence of batteries for ensuring data transfer from sensors to a server for further data processing and storage. In addition to that, it is necessary to provide control subsystems allowing to confirm the operating condition of hightech sensors that have high production cost; and in case of sensor failure, it is required to ensure their replacement or repair within the shortest possible time. When controlling flooding with the help of satellite systems, the accuracy is significantly reduced due to low resolution of satellite photography and additional restrictions imposed by regulatory authorities.

Mere substitution of electronic sensors by common visual markers with a defined height for marking the level of possible flooding and with special marking (for example, a colour marker or pattern) easily recognizable from an aircraft can ensure the operation of the system without the necessity of replacing or repairing for decades.

To carry out the video surveillance of such markers, it is necessary to ensure their routine observation allowing to maintain the prompt delivery of up-to-date information.

This article considers the ways of controlling flood levels by ensuring the video surveillance of markers with the help of satellite systems or remotely piloted aircraft (RPA) systems.

\section{Results}

The article shows the advantages of using RPA for operational determination of flooded areas compared to satellite observation. The monitoring system consists of three components. There are: simplest terrain markers without electronics (and respectively, markers do not need power supplies); RPA, allowing to observe and photograph the area at any time; and specially developed software Cartographic Information System (CIS) to determine the existence and coordinates of the markers, as well as to compare the found parameters with the template ones (in area without flooding). After that, the system gives the result to the operator about presence of flooding with all the necessary parameters, which are calculated, based on the obtained and previous data (height of flooding, speed, intensity). Due to the use of the simplest markers and RPA instead of satellite observation or aviation, the cost of the newly proposed system is minimized.

\section{Acknowledgements}

This work has been supported by the European Regional Development Fund within the Activity 1.1.1.2 "Post-doctoral Research Aid" of the Specific Aid Objective 1.1.1 "To increase the research and innovative capacity of scientific institutions of Latvia and the ability to attract external financing, investing in human resources and infrastructure" of the Operational Programme "Growth and Employment" (No. 1.1.1.2/VIAA/1/16/176 "Multifunctional Nanostructured Coatings for Aircraft Structures (NANOCOAIRS)")

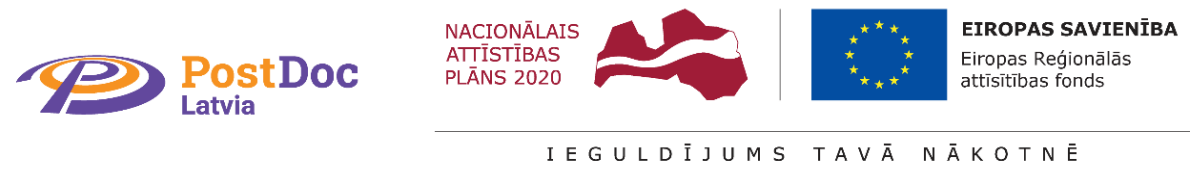

\section{References}

[1] Podnieks M. ArcGIS tehnologiju pielietojums VAS “Latvijas Valsts ceļi” (Application of ArcGIS Technologies in "Latvian State Roads"). (In Latvian) [online], [09.02.2019]. Available at: http://www.envirotech.lv/_s/media/2015/M_Podnieks_LVC_ArcGIS_pielietojums_LVC.pdf 
[2] Urbahs A., Žavtkēvičs V. Remotely Piloted Aircraft route optimization when performing oil pollution monitoring of the sea aquatorium. Aviation, vol. 21(2), 2017, pp. 70-74. DOI: 10.3846 /16487788.2017.1344139.

[3] Urbahs A., Zavtkevics V. Remote Piloted Aircraft Using for Sampling of Oil Spill. Transport Means 2017: Proceedings of the 21st International Scientific Conference, Lithuania, Kaunas, 2022 September 2017. Kaunas: Kaunas University of Tehnology: pp. 489-492. ISSN 1822-296X.

[4] Urbahs A., Jonaite I. Features of the use of unmanned aerial vehicles for agriculture applications. Aviation, vol. 17(4), 2013, pp. 170-175. DOI: 10.3846/16487788.2013.861224. ISSN 1648-7788.

[5] ĢIS produktu un pakalpojumu kopa, kuru izstrādā un attīsta AS "Latvijas valsts meži”" (Set of GIS products and services developed by "Latvian State Forest"), [online], [09.02.2019]. Available from: https://www.lvmgeo.lv/kartes

[6] Latvijas plūdu riska kartes (LVĢMC) (Flood risk maps of Latvia (Latvian Environment, Geology and Meteorology Center)) [online], [09.02.2019]. Available from: https://www.arcgis.com/ home/search.html $? \mathrm{t}=$ content $\& \mathrm{q}=$ tags $\% 3$ ALatvijas $\% 20$ plūdu $\% 20$ riska $\% 20$ kartes\&start $=1 \&$ sortOrder $=$ true \&sortField $=$ relevance

[7] Sunkpho J., Ootamakorn C. Real-time flood monitoring and warning system, Songklanakarin Journal of Science and Technology 33(2), 2011, pp. 227-235, ISSN 0125-3395

[8] Flood Warning Systems In the United States [online], [09.02.2019]. Available from: https://www.fondriest.com/environmental-measurements/environmental-monitoringapplications/flood-warning-systems/

[9] NASA Global Flood Monitoring System [online], [09.02.2019]. Available from: https://disasters.nasa.gov/datasets/global-flood-monitoring-system

[10] Merkurjeva G., Merkurjevs J., Sokolov B., Potryasaev S., Zelensov V., Lektauers A. Advanced River Flood Monitoring, Modelling and Forecasting. Journal of Computational Science, vol. 10, 2015, pp. 77-85. ISSN 1877-7503.

[11] Notti D., Giordan D., Caló F., Zucca, F., Galve, J.P. Potential and limitations of open satellite data for flood mapping. MDPI Remote Sensing, vol. 10(11), 2018, article 1673. ISSN 2072-4292.

[12] Giordan D., Manconi A., Remondino F., Nex F. Use of unmanned aerial vehicles in monitoring application and management of natural hazards, vol. 8(1), 2017, pp. 1-4. ISSN 1947-5713.

[13] U.S. Department of Commerce Relaxes Resolution Restrictions DigitalGlobe Extends Lead in Image Quality [online], [23 October 2018]. Available from: https://web.archive.org/web/20140714215709/http://media.digitalglobe.com/press-releases/u-sdepartment-of-commerce-relaxes-resolution-restrictions-digitalglobe-extends--nyse-dgi-1122861

[14] Urbahs A., Gorelikovs D. Applying Remotely Piloted Aircraft Systems for Correcting Electronic Chart Data and Ensuring Safe Navigation. Proceedings of the 22st International Scientific Conference, 03-05 Oktober, 2018, Lithuania, Trakai. Part I, pp. 430-433. ISSN 1822-296X. 